\title{
Descrição de uma espécie nova de Cephalosphaera Enderlein, 1936 da Amazônia (Diptera, Pipunculidae)
}

Bruna Barbosa SOUZA ${ }^{1}$ Rosaly ALE-ROCHA ${ }^{2}$

\section{RESUMO}

Cephalosphaera aurata sp. nov. é descrita, um "checklist" e uma chave de identificação para as espécies neotropicais são apresentados e novos dados de distribuição geográfica para C. miriamae Rafael, 1992 são fornecidos.

PALAVRAS-CHAVE : Sistemática; espécie nova; distribuição.

\section{Description of a new species of Cephalosphaera Enderlein, 1936 from Amazonian Region (Diptera, Pipunculidae)}

\section{ABSTRACT}

Cephalosphaera aurata sp. nov. is described, a checklist and a key to Neotropical species of Cephalosphaera are presented and new geographic records are provided for C. miriamae Rafael, 1992.

KEYWORDS: Sistematic; new species, distribution. 


\section{INTRODUÇÃO}

Pipunculidae é uma família pequena, mas muito distinta da ordem Diptera, superfamília Syrphoidea (Pipunculidae + Syrphydae) (McAlpine, 1989). É cosmopolita e tem atualmente cerca de 1300 espécies descritas em todo mundo, distribuídas em 20 gêneros (De Meyer, 1996; De Meyer e Skevington, 2000; Skevington e Yeates, 2001). Seus representantes são distinguidos pela cabeça grande, esférica ou hemisférica, a qual é extremamente móvel e formada quase completamente pelos olhos compostos. São pequenos (2,0-8,0 $\mathrm{mm}$ ), escuros e de asas longas. As larvas são endoparasitóides de várias famílias de Hemiptera, especialmente Cicadellidae e Delphacidae, e são importantes como agente de controle biológico (Skevington e Yeates, 2001).

O gênero Cephalosphaera Enderlein, 1936 é cosmopolita, caracterizado pelas cerdas ocelares ausentes; cabeça subglobosa; pós-crânio largo; margem posterior do olho normal; escuto e escutelo sem cerdas fortes; cerdas acrosticais ausentes; propleura com cerdas proepisternais dispostas em leque; cerdas dorsocentrais diferenciadas, diminutas; veia M2 presente; tergitos 6 e 7 ocultos sob o tergito 5 , às vezes o tergito 6 é visível dorsalmente.

As espécies neotropicais de Cephalosphaera foram estudadas recentemente por Rafael e Rosa (1991) que descreveram duas espécies da Amazônia brasileira, Rafael (1992) que revisou as espécies conhecidas até então, Rafael (1996) que descreveu uma espécie para a República Dominicana e Rafael e Menezes (1999) que descreveram três espécies para a Costa Rica. Atualmente são conhecidas 18 espécies para a região Neotropical, seis delas registradas para a Amazônia brasileira (De Meyer, 1996).

Descrevemos neste trabalho Cephalosphaera aurata sp. nov. para a Amazônia brasileira, uma chave de identificação e um "cheklist" para as espécies neotropicais são fornecidos e é feito o novo registro de C. miriamae Rafael, 1992 para o estado do Amazonas.

\section{MATERIAL E MÉTODOS}

O material estudado faz parte do acervo da Coleção de Invertebrados do INPA e é proveniente de coletas feitas na Reserva do Km 41 da rodovia ZF3 pertencente ao Projeto Dinâmica Biológica de Fragmentos Florestais - PDBFF, localizada ao norte do município de Manaus, Amazonas, cujo acesso se dá pela BR 174 (Km 64).

Foram estudados 250 indivíduos do gênero Cephalosphaera. A identificação foi feita por meio de chave de identificação de Rafael (1992), através de descrições originais e redescriçóes, e pela análise da terminália. A terminologia adotada nas descrições segue McAlpine (1981).
Para análise da terminália o abdômen foi cortado na altura do terceiro segmento abdominal e a parte destacada foi aquecida por 30 minutos em ácido lático $85 \%$. O material foi guardado em microtubo de genitália contendo glicerina e alfinetado junto ao espécime correspondente. A asa foi destacada do corpo, tratada com xilol e montada entre lamínulas com bálsamo do Canadá e posteriormente fotografada, permanecendo alfinetada junto ao espécime correspondente através de um pequeno pedaço de cartolina colada a um dos lados da lamínula.

\section{RESULTADOS}

\section{CHECKLIST DAS ESPÉCIES NEOTROPICAIS DE Cephalosphaera ENDERLEIN}

C. (Neocephalosphaera) aequatorialis (Becker), EQUADOR, macho

C. (Neocephalosphaera) arnaudi Rafael, MÉXICO, macho

C. (Cephalosphaera) aurata sp. nov., BRASIL (AM), macho e fêmea

C. (Neocephalosphaera) boutropis (Hardy), BRASIL (PR), ARGENTINA, macho e fêmea

C. (Neocephalosphaera) cristata Rafael, BRASIL (SP), macho

C. (Cephalosphaera) fairchildi Rafael, BRASIL (AM), macho

C. (Cephalosphaera) guanacastensis Rafael \& Menezes, COSTA RICA, macho

C. (Cephalosphaera) incomitata (Hardy), ARGENTINA, macho

C. (Cephalosphaera) insularis Rafael, REPÚBLICA DOMINICANA, JAMAICA, macho e fêmea

C. (Neocephalosphaera) jamaicensis (Johnson), JAMAICA, COSTA RICA, macho e fêmea

C. (Cephalosphaera) macroctenia Rafael, COSTA RICA, BRASIL (PA), macho

C. (Neocephalosphaera) miriamae Rafael, BRASIL (AM, PA, PI, SP, PR), macho e fêmea

C. (Cephalosphaera) mocaensis (Hardy), MÉXICO, REPÚBLICA DOMINICANA, macho e fêmea

C. (Cephalosphaera) pacaraima Rafael \& Rosa, BRASIL (RR), macho e fêmea

C. (Cephalosphaera) panamensis (Hardy), COSTA RICA, PANAMÁ, REPÚBLICA DOMINICANA, JAMAICA, macho

C. (Cephalosphaera) procera Rafael \& Menezes, COSTA RICA, macho 
C. (Neocephalosphaera) santiagoensis Rafael, CHILE, macho e fêmea

C. (Neocephalosphaera) semispiralis Rafael \& Rosa, BRASIL (RR), macho

C. (Cephalosphaera) zumbadoi Rafael \& Menezes, COSTA RICA, macho

CHAVE DE IDENTIFICAÇÃO PARA AS ESPÉCIES NEOTROPICAIS DE Cephalosphaera ENDERLEIN (MODIFICADA DE RAFAEL (1992))

1. Fêmures predominantemente amarelos, às vezes manchados de castanho nos ápices ou dorsalmente .2

- Fêmures castanhos a pretos, às vezes com bases e ápices amarelos ou somente o posterior com a base amarela .......10

2. Todos os fêmures amarelos ...3

- Todos os fêmures com mancha dorsal castanha ou fêmur posterior ou médio e posterior com ápices castanhos . . .5

3.Lobo pós-pronotal castanho a preto; coxa anterior amarela, média e posterior castanhas; abdome castanho a preto com pruína cinza na metade distal do tergito 1 e nas laterais do tergito 5 (Fig. $1 \mathrm{~F}$ ); edeago curto (Fig. $3 \mathrm{~F}$ ); guia fálico sem espinhos apicais (Fig. 3 F)

C. guanacastensis

- Lobo pós-pronotal amarelo; todas as coxas castanhas; abdome com banda basal castanho-escura a preta opaca nos segmentos 3 a 5; guia fálico e edeago variáveis....................... 4. Flagelo amarelo com ápice agudo; base da asa com poucas cerdas curtas e fortes; seçẫo entre a célula $\mathrm{dm}$ e a veia $\mathrm{M}_{2}$ mais longa que a veia $\mathrm{dm}$-cu; tergito $5 \mathrm{com}$ mancha de pruína cinza póstero-lateral (Fig. $1 \mathrm{~K}$ ); sintergoesternito 8 não dividido pela área membranosa (Fig. $2 \mathrm{~N}$ ); guia fálico sem espinhos; edeago curto, não espiralado (Fig. $3 \mathrm{~N}$ )

C. panamensis

- Flagelo predominantemente castanho com ápice filiforme; seçấo entre a célula $\mathrm{dm}$ e a veia $\mathrm{M}_{2}$ maior ou igual à veia $\mathrm{dm}$-cu; base da asa sem cerdas fortes; tergito 5 sem área de pruína cinza póstero-lateral (Fig. $1 \mathrm{C}$ ); área membranosa dividindo o sintergoesternito 8 dorsal e ventralmente (Fig. 2 C); guia fálico com espinhos; edeago longo e espiralado (Fig. 3 C e D) C. boutropis 5 Fêmures amarelos com face dorsal castanha ............ C. semispiralis

- Fêmures anterior amarelo e posterior e médio com ápices castanhos, ou somente o posterior com ápice castanho ...............6

6. Fêmur posterior com ápice castanho; tergitos 2 a 5 com banda basal estreita preta interrompida dorsalmente; guia fálico com projeçẫo apical (Fig. $3 \mathrm{H}$ )

C. insularis

- Fêmures médio e posterior com ápices castanhos; tergitos 2 a 5 com pruína castanha na margem basal formando desenhos quadrangulares ou triangulares e não interrompida dorsalmente ....7
7. Coxa anterior mais clara que a média e posterior; seção entre a célula $\mathrm{dm}$ e a veia $\mathrm{M}_{2}$ mais longa que a veia $\mathrm{dm}$-cu; escutelo castanho a castanho-claro; edeago com todos os ramos igualmente longos .... ...8

- Todas as coxas pretas; seçáo entre a célula $\mathrm{dm}$ e a veia $\mathrm{M}_{2}$ menor ou igual a veia $\mathrm{dm}$-cu; escutelo amarelo; ramo central do edeago mais curto que os demais (Fig. $3 \mathrm{~K}$ )

C. miriamae

8. Tergito 1 amarelo a castanho-claro; tergito 2 com banda basal de pruína castanha quadrangular; triângulo frontal com pruína cinzaprateada; surstilos semissimétricos a simétricos

...9

- Tergito 1 cinza; tergito 2 com banda basal de pruína castanha triangular (Fig. $1 \mathrm{~J}$ ); triângulo frontal preto fosco; surstilos assimétricos (Fig. $2 \mathrm{M}$ ). C. pacaraima 9. Tergito 1 sem mancha basal de pruína castanha (Fig. 1 L) ... C. procera - Tergito 1 com mancha triangular basal de pruína castanha (Fig. 4 B) C. aurata sp. nov. 10. Fêmures castanhos a pretos. . .11

- Fêmures castanhos a pretos com bases e ápices amarelos ou somente o posterior com a base amarela . .12 11. Triângulo frontal com um pequeno calo preto brilhante; sintergoesternito 8 não dividido pela área membranosa (Fig. $2 \mathrm{G}$ ); edeago curto e ramificado (Fig. $3 \mathrm{G}$ ).

C. incomitata

- Triângulo frontal sem calo; área membranosa dividindo o sintergoesternito 8 ventralmente (Fig. 2 P); edeago longo e ramificado (Fig. 3 P)

C. santiagoensis

12 Fêmures anterior e médio castanhos, somente o posterior com a base amarela; tíbia posterior amarela com anel mediano mais claro; sintergoesternito 8 com crista proeminente na área membranosa (Fig. 1 D)

C. cristata

- Todos os fêmures com bases e ápices amarelos; tíbia posterior amarela a preta, sem anel mediano mais claro; sintergoesternito 8 sem crista proeminente na área membranosa 13

13. Tíbias amarelas; lobo pós-pronotal castanho a preto; surstilos mais curtos ou táo longos quanto o epândrio, sem estreitamento pré-apical ou com estreitamento progressivo em direção ao ápice.

- Tíbias castanhas a pretas; lobo pós-pronotal amarelo; surstilos longos e delgados, mais longos que o epândrio, distintamente estreitados na porção pré-apical (Fig. 2 Q).... C. zumbadoi 14. Terceira seçáo costal muito curta, aproximadamente $1 / 6$ da quarta; flagelo castanho a preto, longo e agudo abaixo; sintergoesternito 8 dividido ventralmente pela área membranosa (Fig. $2 \mathrm{~A}$ ) C. aequatorialis

- Terceira seção costal subigual ou táo longa quanto a quarta; flagelo amarelo, castanho ou preto; sintergoesternito 8 variável .......... 15 15. Fêmur posterior com longo ctenídeo ântero-ventral; cerda escutelar moderadamente longa, cerca da metade do comprimento do escutelo medianamente; tíbia posterior com 

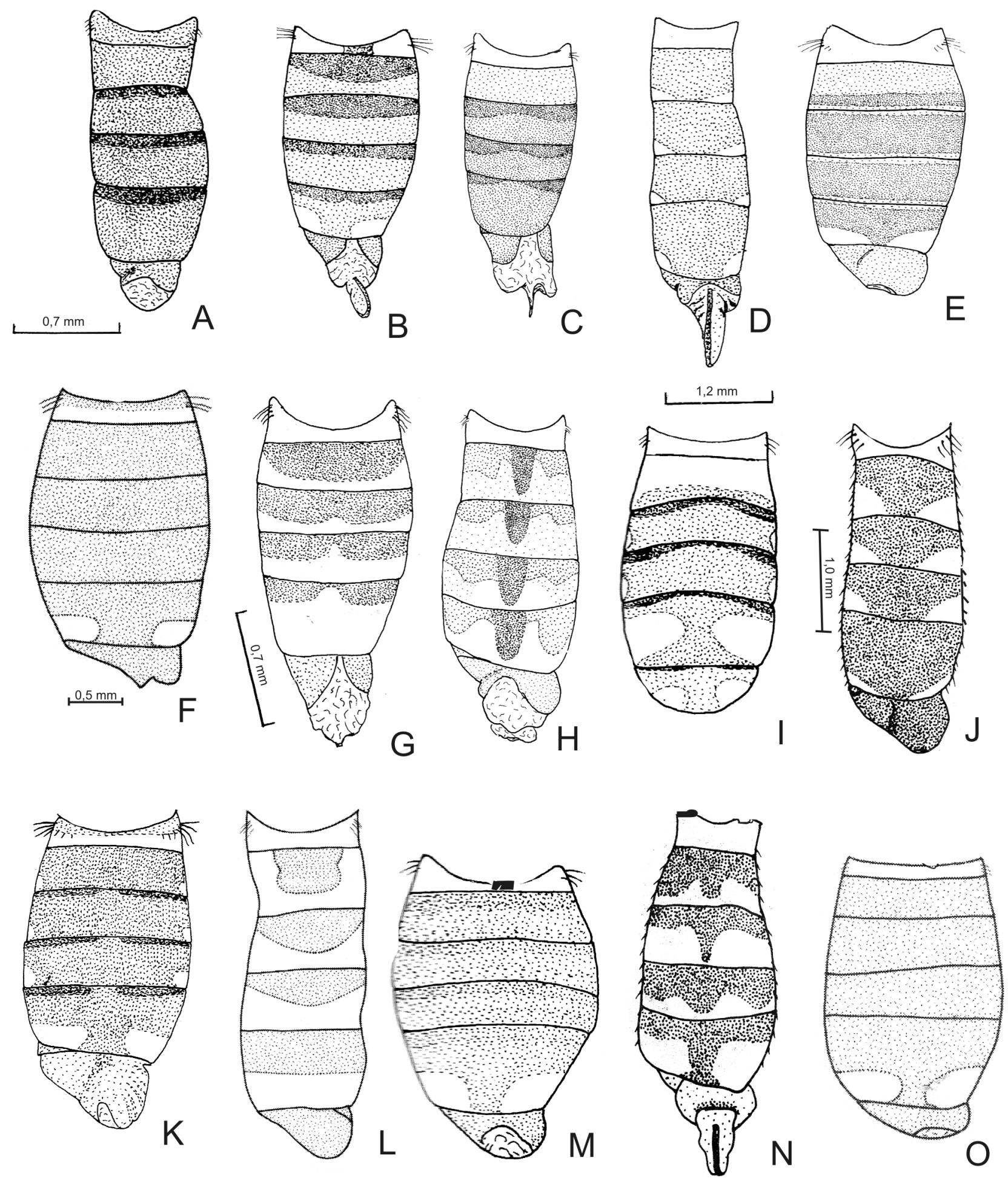

Figura 1 - Abdômen, vista dorsal. A - C. aequatorialis; B - C. arnaudi; C - C. boutropis; D - C. cristata; E - C. fairchild; F - C. guanacastensis; G - C. jamaicensis; H - C. miriamae; I - C. mocaensis; J - C. pacaraima; K - C. panamensis; L - C. procera; $\mathbf{M}$ - C. santiagoensis; $\mathbf{N}$ - C. semispiralis; $\mathbf{0}$ - C. zumbadoi. (figuras de Rafael \& Rosa, 1991; Rafael, 1992, 1994; Rafael \& Menezes, 1999). 

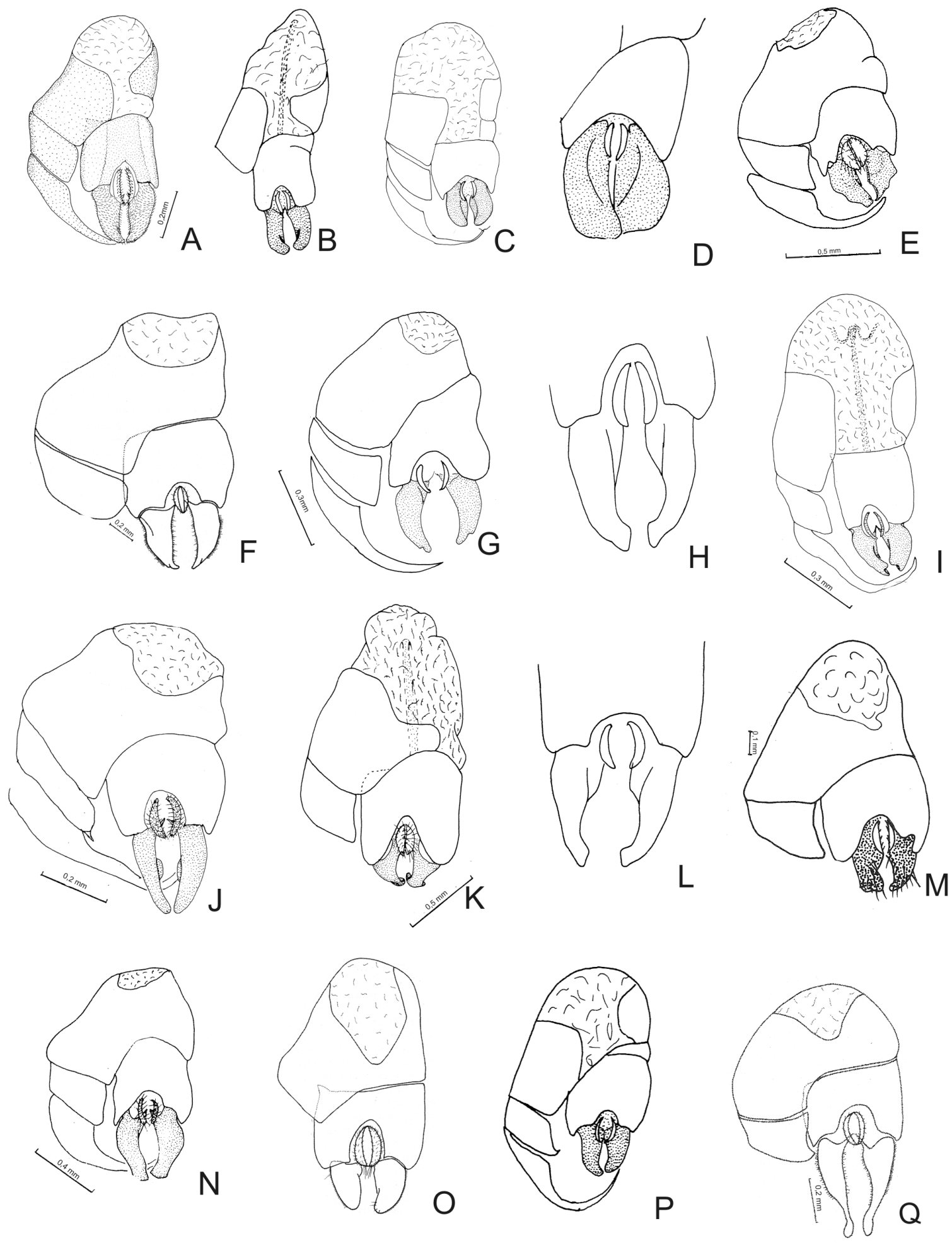

Figura 2 - Terminália masculina, vista ventral. A - C. aequatorialis; B - C. arnaudi; C - C. boutropis; D - C. cristata; E - C. fairchild; F - C. guanacastensis; G - C. incomitata; H- C. insularis; I - C. jamaicensis; J - C. macroctenia; K - C. miriamae; L - C. mocaensis; M- C. pacaraima; $\mathbf{N}$ - C. panamensis; $\mathbf{0}$ - C. procera; P - C. santiagoensis; Q - C. zumbadoi. (figuras de Rafael \& Rosa, 1991; Rafael, 1992, 1994; Rafael \& Menezes, 1999). 

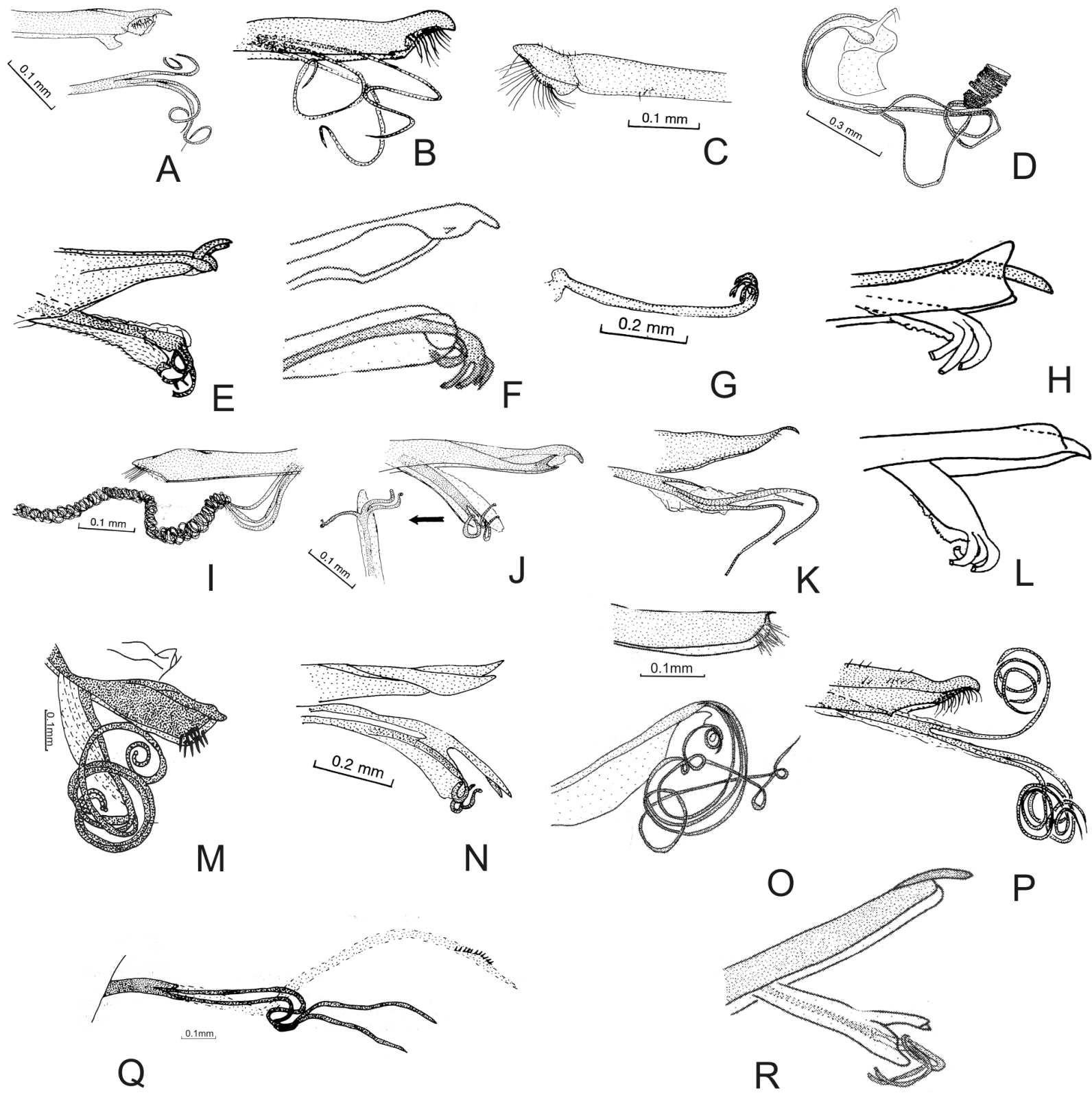

Figura 3 - Guia fálico e edeago, vista lateral. A - C. aequatorialis; B - C. arnaudi; C - C. boutropis; D - C. boutropis; E - C. fairchild; F - C. guanacastensis; G - C. incomitata; H - C. insularis; I - C. jamaicensis; J - C. macroctenia; K - C. miriamae; L - C. mocaensis; M - C. pacaraima; N - C. panamensis; $\mathbf{0}$ - C. procera; P - C. santiagoensis; Q - C.semispiralis; R - C. zumbadoi. (figuras de Rafael \& Rosa, 1991; Rafael, 1992, 1994; Rafael \& Menezes, 1999).

cerdas posteriores eretas medianamente; seção entre a célula $\mathrm{dm}$ e veia $\mathrm{M}_{2}$ mais longa que a veia $\mathrm{dm}$-cu; sintergoesternito 8 não dividido pela área membranosa (Fig. 2J). C. macroctenia - Todos ctenídeos ventrais pequenos subiguais em comprimento; cerda escutelar de tamanho variável; seção entre a célula dm e veia $M_{2}$ maior ou igual que a veia $\mathrm{dm}$-cu; sintergoesternito 8 dividido ou não pela área membranosa.
16. Pedicelo castanho, flagelo amarelo; seção entre a célula dm e veia $\mathrm{M}_{2}$ mais longa que a $\mathrm{dm}$-cu; sintergoesternito 8 náo dividido pela área membranosa

- Pedicelo e flagelo castanhos a pretos; seção entre a célula dm e veia $\mathrm{M}_{2}$ aproximadamente maior ou igual a $\mathrm{dm}$-cu (exceto em jamaicensis); sintergoesternito 8 dividido dorsoventralmente pela área membranosa 18 
17. Flagelo filiforme abaixo; longa cerda escutelar aproximadamente $1 / 3$ da metade do tamanho do escutelo; tergitos 3-5 com faixa preta opaca basal (Fig. 1 I) C. mocaensis

- Flagelo agudo abaixo; cerdas escutelares diminutas, tergitos predominantemente preto brilhantes (Fig. $1 \mathrm{E}$ )

C. fairchildi

18. Seção entre a célula dm e veia $M_{2}$ maior do que a veia dm-cu; área membranosa do sintergoesternito 8 sem crista (Fig. 2 I); edeago longo e espiralado (Fig. $3 \mathrm{I}$ ); tíbia posterior sem cerdas posteriores eretas medianamente C. jamaicensis

- Seção entre a célula $\mathrm{dm}$ e veia $\mathrm{M}_{2}$ aproximadamente igual ao tamanho da veia $\mathrm{dm}$-cu; área membranosa do sintergoesternito 8 com crista proeminente (Fig. 2 B); edeago não espiralado (Fig. $3 \mathrm{~B}$ ); tíbia posterior com cerdas posteriores eretas medianamente

C. arnaudi

\section{Cephalosphaera (Neocephalophaera) miriamae Rafael}

Cephalosphaera miriamae Rafael, 1992 :643 (figs 42,9; 42,22; 42,38; 42,56-58; 42,69).

Diagnose. Antena amarela, escutelo e pernas predominantemente amarelos; calo pós-alar com um pequeno espinho preto anteriormente; abdômen predominantemente amarelo; tergito 1 com longas cerdas nas laterais; edeago com ramo central membranoso tão curto quanto os outros dois (Rafael, 1992).

Espécie descrita do estado do Paraná por Rafael (1992). Tem uma ampla distribuiçáo no Brasil, sendo este o primeiro registro da espécie para o estado do Amazonas.

Material Examinado. BRASIL, Am[azonas], Manaus, Res[erva] P[rojeto] D[inâmica] B[iológica] [de] F[ragmentos] F[lorestais], Km 41, Arm[adilha] Suspensa, R. Querino et. al., v.2004, 2 fêmeas; vi.2004, 2 machos, 1 fêmea; vii.2004, 3 fêmeas; viii.2004, 5 fêmeas; ix.2004, 1 macho, 8 fêmeas; x.2004, 2 machos, 8 fêmeas; xi.2004, 3 machos, 18 fêmeas; xii.2004, 7 machos, 39 fêmeas; i.2005, 1 macho, 21 fêmeas; ii.2005, 1 macho, 47 fêmeas; iii.2005, 1 macho, 27 fêmeas; iv.2005, 15 fêmeas (todos depositados no INPA).

Distribuiçáo. Brasil (Amazonas novo registro, Pará, Piauí, São Paulo, Paraná)

Observaçóes. Espécimes de C. miriamae foram coletados em dois diferentes biótopos na reserva do PDBFF no período entre maio de 2004 a junho de 2005. Essa espécie foi mais abundantemente coletada no sub-bosque (206 $=94,93 \%)$, do que pelo dossel $(11=5,06 \%)$, e no interior da floresta $(142=$ $65,43 \%)$ do que na borda $(71=32,71 \%)$. C. miriamae foi mais freqüente no período compreendido entre novembro/2004 e abril/2005, caracterizado por maiores índices de precipitação na regiấo.
Cephalosphaera (Cephalosphaera) aurata sp. nov. (Figs. 4 A-D)

Diagnose. Antena amarela; escutelo castanho-claro; calo pós-alar com pequeno tufo de cerdas amarelas; coxa anterior castanho-clara, média e posterior castanho-escuras; tergitos $1-4$ dourados, brilhantes, tergito 5 com parte basal pretofosca e apical com pruinosidade cinza; sintergoesternito 8 não dividido ventralmente pela área membranosa (macho)

Holótipo macho. Corpo: 5,1 mm Asa: 5,6 mm.

Descriçáo. Cabeça: triângulo frontal com pruinosidade cinza-prateada; triângulo ocelar cinco vezes maior que o tamanho do ocelo mediano em comprimento, com pruinosidade cinza-prateada; escapo castanho-escuro com uma cerda apical dorsal forte; pedicelo amarelo com margem inferior escurecida, com 2-3 cerdas dorsais, pretas e fortes; flagelo amarelo, duas vezes maior que o pedicelo, com ápice agudo; face com pruinosidade prateada densa. Tórax: escuto castanho-escuro com pruinosidade castanho-clara e cerdas amarelas, delgadas, muito curtas, inconspícuas; lobo pós-pronotal amarelo; notopleura castanho-clara a amarela com densa pruinosidade amarela pálida e algumas cerdas marrons, curtas e delgadas; calo pós-alar com pequeno tufo de cerdas amarelas curtas e delgadas; escutelo castanho-claro com pruinosidade castanha, dois pares de cerdas marginais delgadas, amarelas e curtas, sendo o par apical mais forte; mesopleura castanha com fina pruinosidade amarela pálida mais densa no catatergito e anatergito; meron e metade inferior do catepisterno castanho-claro a amarelo. Pernas: coxa anterior castanho-clara, média e posterior castanho-escuras; coxa média com tufo de cerdas castanhas conspícuas na face anterior; trocanter amarelo com uma cerda dorsal preta alongada; fêmur anterior amarelo, médio e posterior amarelos com um anel castanho pré-apical mais largo na face dorsal; ctenídeos ventrais presentes na metade distal dos fêmures; tíbias amarelas; tarso anterior e médio amarelos, posterior castanho. Asa (Fig. 4A): hialina com iridescência dourada; seção entre a célula $\mathrm{dm}$ e veia $\mathrm{M}_{2}$ maior que a veia $\mathrm{dm}$-cu; lobo anal desenvolvido; veia $\mathrm{dm}$-cu levemente curva; última seção da veia $M_{1}$ curva para cima; base da asa com pequeno grupo de cerdas castanhas delgadas, amarelas e curtas e uma cerda espiniforme preta e robusta; halter esbranquiçado. Abdômen: oval, alongado; tergitos 1-4 amarelo - dourados com mancha basal de pruinosidade castanho-escura a preta; base do tergito 5 castanho-escuro a preto, fosco, e cerca de 1/3 apical com pruinosidade cinza (Fig. 4 B); tergito 1 com cerdas fortes nas laterais. Terminália: sintergoesternito 8 mais curto que o tergito 5; área membranosa não dividindo o sintergoesternito 8 (Figura 4C); surstilos largos e simétricos (Fig. 4 C); guia fálico curto com um grupo de espinhos fortes na ponta (Figura $4 \mathrm{D}$ ); edeago tri-ramificado, longo e enovelado (Figura 4 D). 

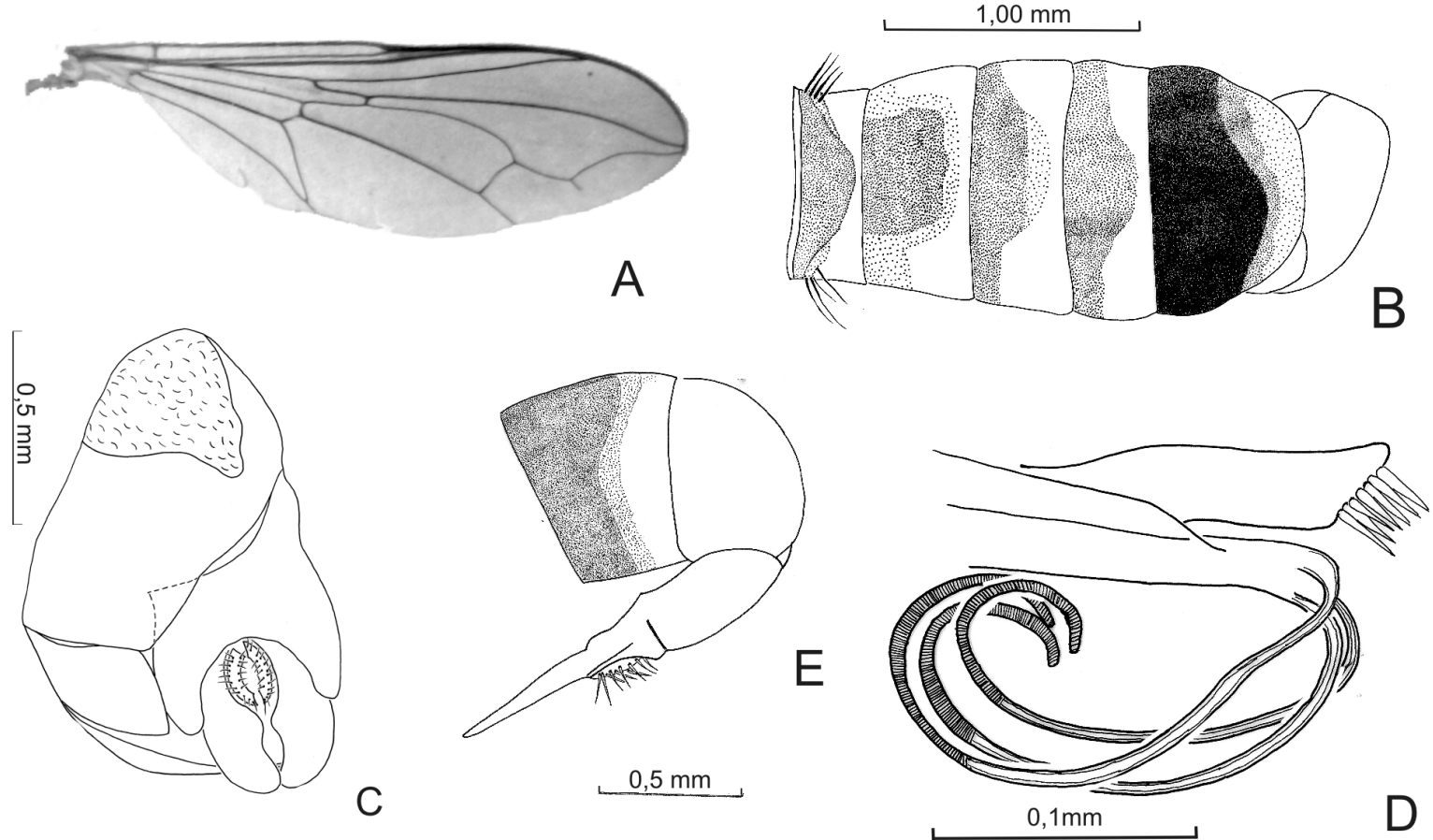

Figura 4 - Cephalosphaera sp. nov. (Parátipo macho). A - Asa. B - Abdômen. C - Terminália masculina, vista ventral. D- Ápice do guia fálico e edeago, vista lateral. E - terminália feminina, vista lateral.

Fêmea. Como no macho, exceto pelos olhos dicópticos. Terminália: ovipositor longo quase alcançando a base do esternito 2 (Fig. 4 E).

Material Examinado. Holótipo Macho (INPA), BRASIL, Am[azonas], Manaus, Reserva Km 41, P[rojeto] D[inâmica] $\mathrm{B}$ [iológica] de F[ragmentos] F[lorestais], Trilha LL B[orda] S[ub] B[osque], 19- 21.i.2005, Ranyse Querino (INPA).

Parátipos. BRASIL, Am[azonas], Manaus, Reserva Km 41, P[rojeto] D[inâmica] B[iológica ] de F[ragmentos] F[lorestais], [sem trilha], Arm[adilha] Suspensa, Dossel, 2627.v.2004, R. Querino, S. Costa, A. Nazareno, L. Queiroz, M. Feitosa, Q. Pereira cols, 1 macho (INPA); Sub-bosque, 23-24.vi.2004, J. Deus cols, 1 macho; Trilha LL B-SB, 21- 22.vii.2004, 1 macho e 1 fêmea; Trilha R I[nterior]-SB, 18-19.viii.2004, 1 macho; Trilha AB B-D, 29-30.ix.2004, 1 macho e 1 fêmea; Trilha AB B-SB, 15-16.ix.2004, 1 fêmea; Trilha C I-SB, 01-02.ix.2004, 1 macho; Trilha EE, B-SB, 15-16.ix.2004, 1 macho; Trilha EE B-D, 23-30.ix.2004, 1 macho; Trilha LL I-[sem altura], 29-30.ix.2004, 1 fêmea; Trilha R I-D, 01-02.ix.2004, 1 fêmea; Trilha R B-SB, 01-02. ix.2004, 2 machos (depositados no INPA); Trilha R I-SB, 15-16.ix.2004, 1 macho; Trilha R I-D, 29-30.ix.2004, 1 fêmea; Trilha AB I-SB, 13- 14.x.2004, 1 macho; Trilha LL
B-SB, 27-28.x.2004, 2 fêmeas (depositados na USP); Trilha R I-SB, 27-28.x.2004, 1 macho e 1 fêmea; Trilha AB B-SB, 10-12.xi.2004, 1 fêmea; Trilha AB B-SB, 08-09.xii.2004, R. Querino, 1 macho; Trilha AB I-SB, 19-21.i.2005, 1 fêmea; Trilha I B-SB, 19-21.i.2005, 1 fêmea; Trilha C B-D, 16-17. ii.2005, 1 macho; Trilha AB B-SB, 16-18.iii.2005, 1 fêmea; Trilha R B-D, 16-18.iii.2005, 1 fêmea; Trilha LL I-D, 02-04. iv.2005, 1 fêmea; Trilha EE B-SB, 22.xii - 07.xi.2005, 1 macho (depositados no INPA).

Distribuiçáo. Brasil (Amazonas).

Etimologia. O nome específico é derivado do latim: aurum = dourado, e refere-se a pruinosidade dourada do abdômen.

\section{DISCUSSÃO}

Cephalosphaera aurata sp. nov. é similar a C. panamensis Hardy com os seguintes caracteres em comum: fêmur amarelo; calo pós-alar com diminuta cerda delgada; seção entre a célula $\mathrm{dm}$ e veia M2 mais longa que a veia $\mathrm{dm}$-cu; flagelo amarelo com ápice agudo; base da asa com poucas cerdas fortes curtas; sintergoesternito 8 não dividido pela área membranosa. São distinguidas principalmente pela cor do pedicelo, abdômen e a terminália, onde $C$. aurata sp. nov possui pedicelo castanho 
ao contrário de C. panamensis que é castanho-escuro a preto; tergitos 1-4 dourados com mancha basal de pruinosidade castanho-escura enquanto em $C$. panamensis os tergitos são marrons, o tergito 1 tem pruinosidade castanho-escura na metade basal e cinza na metade distal e os tergitos 3-5 têm bandas basais pretas, opacas, estreitas e interrompidas dorsalmente, com mancha lateral de pruinosidade cinza posteriormente; tergito $5 \mathrm{com}$ parte basal preta, e apical completamente coberta de pruinosidade cinza, enquanto que o tergito 5 de $C$. panamensis apresenta pruinosidade cinza póstero-lateralmente. Além disso, ambas podem ser distinguíveis facilmente pelos caracteres da terminália masculina. Os surstilos de $C$. aurata sp. nov. sáo semelhantes aos de C. boutropis (Hardy) e C. santiagoensis, mas ambas tem o sintergoesternito 8 dividido pela área membranosa diferenciando-se assim de C. aurata sp. nov. A mesma, apresenta surstilos e coloração do abdômen semelhante a $C$. procera sp.nov., mas difere desta pela coloração do tergito 1 , surstilos mais simétricos e mais largos e pelas cerdas do ápice do guia fálico que são espiniformes.

Observaçôes. Espécimes de C. aurata sp. nov. foram coletados em dois diferentes biótopos na reserva do PDBFF no período entre maio de 2004 a junho de 2005. Essa espécie foi mais abundantemente coletada no sub-bosque $(25=$ $75,93 \%)$, do que pelo dossel $(8=24,24 \%)$, e na na borda ( 17 $=51,51 \%)$ do que no interior da floresta $(13=39,393 \%)$. $C$. aurata sp. nov. foi mais freqüente no mês de setembro/2004, mês caracterizado por baixa precipitaçáo na regiáo.

\section{AGRADECIMENTOS}

A Dra. Ranyse Querino da Embrapa (Roraima) e colaboradores pela coleta do material e ao Dr. José Albertino Rafael pelas sugestôes quanto ao conteúdo do trabalho.

\section{BIBLIOGRAFIA CITADA}

McAlpine, J. F. 1981. Morphology and terminology: adults. In: McAlpine, J. F.; Peterson, B. V. et al. eds. Manual of Neartic
Diptera. Ottawa, Research Branch, Agriculture Canada. v. 1, p. 9-63. (Monograph n²7).

McAlpine, J. F. 1989. Manual of Neartic Diptera (volume 3). Biosystematics Research Centre (formely Institute), Otawa. $1521 \mathrm{pp}$.

De Meyer, M. 1996. World catalogue of Pipunculidae (Diptera). Institut royal des Sciences naturelles de Belgique, Documents de Travail, 86:1-127.

De Meyer, M. ; Skevington, J.H. 2000. First addition to the World Catalogue of Pipunculidae (Diptera). Bulletin de l'Institut Royal des Sciences Naturelles de Belgique, Entomologie, 70:5-11.

Rafael, J.A. 1992. Review of the neotropical of big-headed flies, genus Cephalosphaera (Diptera: Pipunculidae). In:Quintero, D.; Aiells, A. (Eds). Insects of Panama and Mesoamerica: selected studies. 1 ed. Oxford: Oxford University Press. p. 633-646.

Rafael, J.A. ; Rosa, M.S.S. 1991. Pipunculidae (Diptera) da Estação Ecológica de Maracá e da localidade de Pacaraíma, Roraima, Brasil. Acta Amazonica, 21 (único) : 337-350.

Rafael, J.A. 1996. Pipunculidae (Insecta : Diptera) of the Dominican Republic : New records and description of new species. Annals of Carnegie Museum, 65 (4) : 363-381.

Rafael, J.A. ; Menezes, M.D.S. 1999. Taxonomic review of Costa Rican Pipunculidae (Insecta: Diptera). Revista de Biologia Tropical, 47(3): 513-534.

Skevington, J.H.; Yeates, D.K. 2001. Phylogenetic classification of Eudorylini (Diptera: Pipunculidae). Systematic Entomology, 26:421-452.

Recebido em 22/04/2009

Aceito em 06/08/2009 
